\title{
Possible virulence factors involved in bacteraemia caused by Aeromonas hydrophila
}

\author{
J. VADIVELU, S. D. PUTHUCHEARY*, M. PHIPPS and Y. W. CHEE \\ Department of Medical Microbiology, Faculty of Medicine, University of Malaya, 59100 Kuala Lumpur, Malaysia
}

\begin{abstract}
Summary. Eighteen strains of Aeromonas hydrophila from patients with bacteraemia were investigated for possible virulence factors. Cytotoxin and haemolysin were produced by all strains, whereas cholera toxin-like factor was produced by $33 \%$ of strains only. Enterotoxin production was not detected. Haemagglutination of guinea-pig, fowl and rabbit erythrocytes was demonstrated by $83 \%, 67 \%$ and $61 \%$ of strains, respectively. Fucose- and mannosesensitive haemagglutinins were predominant. None of the strains agglutinated sheep erythrocytes. Extrachromosomal DNA was detected in 17 strains, 16 of which had a plasmid (3.6-5.1 MDa), the majority being between $4 \cdot 6$ and 5.1 MDa.
\end{abstract}

\section{Introduction}

Aeromonas hydrophila, a member of the family Vibrionaceae, is increasingly recognised as a pathogen of man and gives rise to both intestinal and extraintestinal infections. ${ }^{1-3}$ The natural habitat of aeromonads is aquatic; the species can multiply in fresh and drinking water and give rise to infections in fish, turtles, alligators and other fresh water animals. ${ }^{4}$ The range of human extra-intestinal infections is from traumatic introduction of the micro-organisms into the skin, with resultant necrotising cellulitis, to opportunist systemic infections in immunocompromised patients.

Several potential virulence factors elaborated by Aeromonas spp. have been described. These include cytotoxin and haemolysin, which appear to be the same protein or very closely related, ${ }^{5}$ an enterotoxin, cholera toxin-like factor (CTF) and haemagglutinins. The pathogenic role of these factors remains unclear.

An earlier study ${ }^{3}$ that compared the exotoxin profiles of intestinal and extra-intestinal strains found haemolysin and cytotoxin to be produced by most strains, irrespective of their origin. Enterotoxin was produced by $c$. 10-20\% of enteric and wound isolates only. The production of CTF was most frequent in enteric isolates. Of the six bacteraemic strains studied, the haemolysin and cytotoxin were produced in combination in three strains and singly in the other three. Enterotoxin was not produced by any of these

Received 28 Feb. 1994; revised version received 24 June 1994; accepted 28 Sept. 1994.

* Correspondence should be sent to Professor S. D. Puthucheary. strains and CTF by only one. These findings were interpreted with caution because numbers were small.

In this study, a further 18 bacteraemic strains of $A$. hydrophila were investigated to ascertain which of the virulence factors, if any, were involved in the pathogenesis of septicaemia.

\section{Materials and methods}

Eighteen strains of $A$. hydrophila from patients at the University Hospital, Kuala Lumpur, Malaysia were examined. All were isolated in biphasic blood culture media (bioMérieux) from patients with bacteraemia and identified by standard bacteriological methods ${ }^{6}$ as belonging to the genus Aeromonas. These strains were then confirmed and speciated by the API 20 E system (bioMérieux). Although the API 20E does not reliably distinguish aeromonads, the property of inability to grow in the presence of $\mathrm{NaCl} 8 \%$ and resistance to the vibriostatic agent $\mathrm{O} / 129$ excluded Vibrio fluvialis; non-production of gas from glucose excluded $A$. caviae and a negative aesculin hydrolysis test excluded $A$. sobria. In addition, the analytical profile index obtained by the API $20 \mathrm{E}$ system was $\geqslant 99.0 \%$, confirming that these strains were $A$. hydrophila. The strains were stored at room temperature on Tryptone Soy Agar (Oxoid) slopes during the course of the study. Escherichia coli WF5 (University of Surrey, UK) was used as the negative control in the detection of haemolysin, cytotoxin and enterotoxin. Cholera toxin (Sigma) $1 \mathrm{mg} / \mathrm{L}$ was used as the positive control for enterotoxin activity (vero cells) and CTF activity (ELISA). 
Patients' records were reviewed for data such as age, sex, underlying illness and other relevant predisposing factors such as burns and trauma. No attempt was made to obtain faecal isolates from these patients as this was a retrospective study.

\section{Preparation of culture filtrates}

Cell-free culture supernates were prepared with Brain Heart Infusion Broth (Oxoid) by the method of Cumberbatch et al. ${ }^{7}$ as described previously. ${ }^{3}$ The filter-sterilised cell-free supernates were stored at $-20^{\circ} \mathrm{C}$ in small volumes and tested within 1 week of preparation.

\section{Cytotoxin and enterotoxin assay}

The vero cell assay for the detection of cytotoxin and enterotoxin activity was performed as described previously. ${ }^{3}$ Cytotoxin activity was determined when $\geqslant 50 \%$ cells were lysed when exposed overnight at $37^{\circ} \mathrm{C}$ to $50 \mu \mathrm{l}$ of cell-free supernate. Enterotoxin activity was detected when $\geqslant 50 \%$ cells showed morphological cytopathic effects when exposed overnight at $37^{\circ} \mathrm{C}$ to $50 \mu \mathrm{l}$ of cell-free supernate heated at $56^{\circ} \mathrm{C}$ for $10 \mathrm{~min}$ to denature the cytotoxin.

\section{Cholera toxin-like factor assay}

The enzyme-linked immunosorbent assay (ELISA) method of Sack et al. ${ }^{8}$ modified by Miller et al. ${ }^{9}$ was performed as described previously. ${ }^{3}$ The results were read spectrophotometrically at $492 \mathrm{~nm}$ with a Dynatech MR600 Microelisa reader. A negative: positive cut-off value was calculated from the average values of control negative strains $+2 \mathrm{SD}$ values. $^{10}$

\section{Haemagglutination assay}

The haemagglutination assay was performed by the method of Crichton and Walker. ${ }^{11}$ The presence of haemagglutinins was determined with fresh erythrocytes from sheep, rabbit, guinea-pig and fowl in the presence or absence of L-fucose (Sigma) $2 \% \mathrm{w} / \mathrm{v}$ and mannose (BDH Chemicals) $2 \% \mathrm{w} / \mathrm{v}$. The erythrocytes were prepared by centrifuging $10 \mathrm{ml}$ of blood collected in an equal volume of sterile Alsevier's solution. The resultant supernate was discarded, the packed cells were washed twice in sterile phosphatebuffered saline (PBS) and resuspended to $3 \% \mathrm{v} / \mathrm{v}$ in fresh PBS. For haemagglutinin production, the bacterial strains were grown on human blood agar (Oxoid) at $37^{\circ} \mathrm{C}$ for $24 \mathrm{~h}$ and harvested directly in PBS at a concentration of $10^{11} \mathrm{cfu} / \mathrm{ml}$. Bacterial suspension $(25 \mu \mathrm{l})$ was added to $25 \mu 1$ of erythrocyte suspension and $25 \mu \mathrm{l}$ of PBS in a depression on a porcelain tile, rocked at ambient temperature for $10 \mathrm{~min}$ and observed for haemagglutination. Parallel tests were performed in which the PBS was substituted with $25 \mu \mathrm{l}$ of L-fucose or mannose $2 \% \mathrm{w} / \mathrm{v}$. Haemagglutination reactions were recorded as weakly $(+)$, moderately $(++)$ or strongly $(+++)$ positive, or negative $(-)$.

\section{Plasmid analysis}

Plasmids were isolated by the method of Kado and Liu. ${ }^{12}$ Briefly, $1 \mathrm{ml}$ of overnight culture incubated at $37^{\circ} \mathrm{C}$ was centrifuged for $10 \mathrm{~min}$ at $12000 \mathrm{rpm}$. The pellet was thoroughly resuspended in $100 \mu$ l of lysing buffer (SDS 3\%, $50 \mathrm{~mm}$ Tris, pH 12.6) and incubated at $65^{\circ} \mathrm{C}$ for $1 \mathrm{~h}$ with occasional mixing. Subsequently, $200 \mu 1$ of unbuffered phenol-chloroform (1:1 v:v) was added and the mixture was vortex mixed briefly before centrifugation for $5 \mathrm{~min}$ at $12000 \mathrm{rpm}$ to separate the mixture. The upper aqueous phase was used directly on an agarose $0.6 \%$ gel prepared in Tris-borate-EDTA buffer (1x). The plasmids were electrophoresed through the gel at $130 \mathrm{~V}$ for $2 \mathrm{~h}$ in Tris-borate-EDTA buffer. Plasmids isolated from E. coli strain V517 were used as close circular DNA mol. wt. markers $(7 \cdot 5,18 \cdot 0$, $26 \cdot 0,31 \cdot 0,11 \cdot 5,23 \cdot 0,29 \cdot 5$ and $34 \cdot 0 \mathrm{MDa}$ ).

\section{Results}

The age and sex distribution of the 18 patients (table I) shows an equal distribution of the sexes; the age range was $17-72$, the average being 43 years. All but one of the patients had a severe underlying illness or predisposing risk factor which could be categorised into three groups-leukaemia/lymphoma, seven $(39 \%)$; trauma/burns, six (33\%); and liver cirrhosis, four $(22 \%)$. The case fatality rate was $72 \%$.

All 18 strains of $A$. hydrophila produced haemolytic zones around the colonies on Ox Blood Agar (Oxoid), indicating the elaboration of a haemolysin. These strains were also found to produce cytotoxin. However, none elaborated any enterotoxin. CTF was produced by six strains, four of which were from patients involved in motor vehicle accidents or burns.

The ability of the strains to haemagglutinate was studied with sheep, rabbit, guinea-pig and fowl erythrocytes. Two of the 18 strains showed no haemagglutination; of the remaining 16, eight showed fucose- and mannose-sensitive haemagglutination with rabbit, guinea-pig and fowl erythrocytes only; one strain demonstrated the same pattern with guineapig and fowl erythrocytes and a further two strains with guinea-pig erythrocytes only. The remaining five strains exhibited variable patterns of haemagglutination (table II). None of the strains agglutinated sheep erythrocytes.

Plasmid profiles were obtained for 17 strains that had at least one plasmid (table I). Sixteen strains had at least one plasmid of between 3.6 and 5.1 MDa and the majority were $4 \cdot 6-5 \cdot 1 \mathrm{MDa}$. Three strains had additional plasmids; one strain had $\mathrm{a} \geqslant 62-\mathrm{MDa}$ plasmid, one strain had a $2 \cdot 85-\mathrm{MDa}$ plasmid and a third had two plasmids of 2.95 and $2.6 \mathrm{MDa}$. Of the remaining two strains, one had a larger plasmid of $\geqslant 19 \mathrm{MDa}$ and the other had no plasmids. 
Table I. Age and sex distribution, predisposing factors, outcome, virulence factors and plasmid profiles of septicaemic strains of $A$. hydrophila

\begin{tabular}{cccccccc}
\hline $\begin{array}{c}\text { Patient } \\
\text { no. }\end{array}$ & $\begin{array}{c}\text { Age } \\
\text { (years) }\end{array}$ & Sex & \multicolumn{1}{c}{$\begin{array}{c}\text { Predisposing } \\
\text { factor }\end{array}$} & Outcome & Hly/Cyt & Ent/CTF & $\begin{array}{c}\text { Plasmid } \\
\text { (MDa) }\end{array}$ \\
\hline 1 & 68 & F & Liver cirrhosis & D & $+/+$ & $-/-$ & $4 \cdot 6$ \\
2 & 54 & M & Liver cirrhosis & D & $+/+$ & $-/-$ & $4 \cdot 8 / 2 \cdot 85$ \\
3 & 61 & F & Liver cirrhosis & A & $+/+$ & $-/-$ & $5 \cdot 1$ \\
4 & 50 & M & Liver cirrhosis & A & $+/+$ & $-/-$ & $4 \cdot 8$ \\
5 & 72 & F & Leukaemia/lymphoma & D & $+/+$ & $-/-$ & $4 \cdot 6$ \\
6 & 46 & M & Leukaemia/lymphoma & D & $+/+$ & $-/+$ & $5 \cdot 1$ \\
7 & 24 & M & Leukaemia/lymphoma & D & $+/+$ & $-/-$ & $4 \cdot 8$ \\
8 & 66 & F & Leukaemia/lymphoma & A & $+/+$ & $-/-$ & $4 \cdot 6$ \\
9 & 59 & F & Leukaemia/lymphoma & A & $+/+$ & $-/-$ & $5 \cdot 1$ \\
10 & 56 & F & Leukaemia/lymphoma & D & $+/+$ & $-/-$ & $4 \cdot 8$ \\
11 & 17 & F & Leukaemia/lymphoma & D & $+/+$ & $-/+$ & $5 \cdot 1$ \\
12 & 15 & M & Trauma (MVA/Burns) & A & $+/+$ & $-/+$ & $4 \cdot 8$ \\
13 & 17 & F & Trauma (MVA/Burns) & D & $+/+$ & $-/-$ & $4 \cdot 8 / 2 \cdot 95 / 2 \cdot 6$ \\
14 & 17 & M & Trauma (MVA/Burns) & D & $+/+$ & $-/+$ & $\geqslant 62 / 4 \cdot 8$ \\
15 & 39 & M & Trauma (MVA/Burns) & D & $+/+$ & $-/+$ & $4 \cdot 8$ \\
16 & 49 & M & Trauma (MVA/Burns) & D & $+/+$ & $-/-$ & $3 \cdot 8$ \\
17 & 19 & M & Trauma (MVA/Burns) & D & $+/+$ & $-/+$ & 19 \\
18 & 39 & F & Post-partum death & D & $+/+$ & $-/+$ & - \\
& & & & & &
\end{tabular}

D, died; A, alive; MVA, motor vehicle accident; Hly/Cyt, haemolysin/cytotoxin; Ent/CTF, enterotoxin/cholera toxin-like factor.

Table II. Individual haemagglutination patterns of five septicaemic strains of $A$. hydrophila

\begin{tabular}{|c|c|c|c|c|c|c|c|c|c|}
\hline \multirow{2}{*}{$\begin{array}{c}\text { Strain } \\
\text { no. }\end{array}$} & \multicolumn{3}{|c|}{ Rabbit } & \multicolumn{3}{|c|}{ Guinea-pig } & \multicolumn{3}{|c|}{ Fowl } \\
\hline & $\mathrm{C}$ & $F$ & $\mathbf{M}$ & $\mathrm{C}$ & $\mathrm{F}$ & $\mathbf{M}$ & $\mathrm{C}$ & $\mathrm{F}$ & $\mathbf{M}$ \\
\hline 1 & $1+$ & $1+$ & $1+$ & $2+$ & $2+$ & $2+$ & $1+$ & - & - \\
\hline 2 & - & - & - & - & - & - & $1+$ & $1+$ & $2+$ \\
\hline 3 & - & - & - & $1+$ & - & - & - & - & - \\
\hline 4 & $2+$ & $1+$ & $1+$ & $3+$ & - & - & - & - & - \\
\hline 5 & $2+$ & $1+$ & - & $3+$ & - & - & $1+$ & - & - \\
\hline
\end{tabular}

C, control (erythrocyte only); F, L-fucose; M, mannose.

\section{Discussion}

The ability of $A$. hydrophila to give rise to a wide range of infections in man indicates that complex pathogenic mechanisms that involve a range of protein toxins may be responsible. The wide natural habitat of the organism shows that it can adapt to different environments and suggests the presence of survival mechanisms.

We have shown ${ }^{3}$ that cytotoxin and haemolysin were produced in combination in the majority of clinical isolates, suggesting that this may be an inherent property of $A$. hydrophila, although it was more prominent in the extra-intestinal strains. The production of cytotoxin and haemolysin by all 18 bacteraemic strains in this study supports this view, although the role of these factors in the pathogenesis of infection is unclear. One could speculate that the cytotoxin may play a role in severe, necrotising wound infections and bloody diarrhoea associated with this species.

We were unable to show enterotoxin production in the 18 bacteraemic strains and this corroborates our earlier study. ${ }^{3}$ Although the gene that encodes enterotoxir. production has been shown to be chromosomal, ${ }^{13}$ these bacteraemic strains showed no evidence of enterotoxin production, which suggests that these genes may be cryptic, absent or may be present on transposon(s) with reverse integration and expression of this property may not be necessary in the pathogenesis of bacteraemia.

Toxins similar to the cholera toxin have been found in enteric pathogens such as enterotoxigenic Escherichia coli and Campylobacter jejuni. There is a suggestion that the genes that occur on transferrable plasmids may be exchanged amongst organisms in the gut or the environment. Therefore, strains of $A$. hydrophila could have acquired the genes for CTF production. In this study, CTF was produced by $39 \%$ of strains, $71 \%$ of which occurred amongst strains isolated from patients with trauma or burns. This suggests that the organisms may have originated from an enteric source such as the patients' own gut flora, or from an environmental source during trauma. The absence of enterotoxin and CTF amongst the bloodculture isolates is in agreement with our previous findings and suggests that these toxins may not play a role in the pathogenesis of septicaemia due to A. hydrophila.

The ability to adhere to the intestinal mucosa is an essential early step in colonisation and development of an enteric infection. The role of mannose-resistant haemagglutinins (MR-HA) in colonisation by enterotoxigenic $E$. coli has been reported. ${ }^{14}$ Amongst Aeromonas spp., MR-HA have been found in diarrhoeic isolates, whereas environmental isolates were found to have mannose- and fucose-sensitive haemagglutinins (MS-HA and FS-HA). ${ }^{15}$ In this study, $89 \%$ of strains were found to possess 
haemagglutinins, of which $69 \%$ possessed MS-HA and FS-HA, which suggests that these isolates may have originated from an environmental source. The organisms may have entered the bloodstream directly as a result of trauma or intravenous therapy. In two of these cases, MR-HA was detected (table II) that may have originated from the patients' gut flora. However, the role of these haemagglutinins in disease caused by Aeromonas spp. remains to be defined.

Genetic determinants of the haemolysin, cytotoxin and enterotoxin have been identified on three different segments of the $A$. hydrophila chromosome. ${ }^{13}$ However, the determinants for CTF have not been found. As in other organisms such as $E$. coli, the genes may be located on plasmids. ${ }^{16}$ Plasmids were present in $94 \%$ of strains of $A$. hydrophila, most of which seemed to have a conserved plasmid of $4 \cdot 6-5 \cdot 1 \mathrm{MDa}$. It is not clear whether the CTF gene may be located on this plasmid as not all strains with this plasmid produce CTF. Other factors such as adhesins and antibiotic resistance may be coded on this plasmid but this possibility was not investigated further. Three strains had additional bands, of which two strains had two plasmids and another three plasmids. It is possible that the smaller bands may have been products of shearing of the 4.8-MDa plasmid during preparation. Two of the strains had plasmids of $19 \mathrm{MDa}$ and $\geqslant 62 \mathrm{MDa}$,

\section{References}

1. Daily OP, Joseph SW, Coolbaugh JC et al. Association of Aeromonas sobria with human infection. $J$ Clin Microbiol 1981; 13: 769-777.

2. Janda JM, Reitano M, Bottone EJ. Biotyping of Aeromonas isolates as a correlate to a delineating species-associated disease spectrum. J Clin Microbiol 1984; 19: 44-47.

3. Vadivelu J, Puthucheary SD, Navaratnam P. Exotoxin profiles of clinical isolates of Aeromonas hydrophila. $J \mathrm{Med}$ Microbiol 1991; 34: 363-367.

4. Namdari H. Aeromonas species: pathogens of aquatic inhabitants with a human host range. Clin Microbiol Newsletter 1991; 15: 113-116.

5. Asao T, Kinoshita Y, Kozaki S, Uemura T, Sakaguchi G. Purification and some properties of Aeromonas hydrophila hemolysin. Infect Immun 1984; 46: 122-127.

6. Cowan ST. Cowan and Steele's Manual for the identification of medical bacteria. Cambridge, Cambridge University Press. 1981: 100-101.

7. Cumberbatch N, Gurwith MJ, Langston C, Sack RB, Brunton JL. Cytotoxic enterotoxin produced by Aeromonas hydrophila: relationship of toxigenic isolates to diarrheal disease. Infect Immun $1979 ; 23: 829-837$.

8. Sack DA, Huda S, Neogi PKB, Daniel RR, Spina WM. Microtiter ganglioside enzyme-linked immunosorbent assay for Vibrio cholerae and Escherichia coli heat-labile enterotoxins and antitoxin. J Clin Microbiol 1980; 11: $35-40$. respectively, which may represent chromosomal contamination of the plasmid preparation.

This study supports our earlier findings ${ }^{3}$ that the production of cytotoxin and haemolysin are closely related and universal amongst all strains of $A$. hydrophila isolated from clinical specimens. One possibility is that, although all strains are able to produce haemolysin and cytotoxin, these factors may be less important in the pathogenesis of intestinal infection than the ability of the organism to invade and enter the bloodstream from intestinal or extraintestinal infections. The production of CTF was commoner in strains from cases with trauma or burns that had been contaminated with water and soil. Hence the CTF genes may have been acquired from enteric pathogens in the environment. These strains did not produce enterotoxin, which is further evidence that the encoding genes may be cryptic or lost through the selection process in the pathogenesis of bacteraemia. The presence of a conserved plasmid suggests that it may be useful to investigate the nature of the genes present, which may give further information about the presence of virulence factors and haemagglutinins.

This study was supported by a grant from University of Malaya Vote F144/90 and Glaxo Malaysia Sdn. Bhd. of Malaysia.

9. Miller CJ, Drasar BS, Feachem RG, Hayes RJ. The impact of physico-chemical stress on the toxigenicity of Vibrio cholerae. J Hyg 1986; 96: 49-57.

10. Vadivelu J, Dunn DT, Feachem RG et al. Comparison of five assays for the heat-labile enterotoxin of Escherichia coli. J Med Microbiol 1987; 23: 221-226.

11. Crichton PB, Walker JW. Methods for the detection of haemagglutinins in Aeromonas. J Med Microbiol 1985; 19: 273-277.

12. Kado CT, Liu S-T. Rapid procedure for detection and isolation of large and small plasmids. J Bacteriol 1981; 145: 1365-1373.

13. Chakraborty T, Montenegro MA, Sanyal SC, Helmuth R, Bulling E, Timmis KN. Cloning of enterotoxin gene from Aeromonas hydrophila provides conclusive evidence of production of a cytotoxic enterotoxin. Infect Immun 1984; 46: 435-441.

14. Evans DJ, Evans DG, Dupont HL. Hemagglutination patterns of enterotoxigenic and enteropathogenic Escherichia coli determined with human, bovine, chicken, and guinea-pig erythrocytes in the presence and absence of mannose. Infect Immun 1979; 23: 336-346.

15. Burke V, Robinson J, Cooper $\mathrm{M}$ et al. Biotyping and virulence factors in clinical and environmental isolates of Aeromonas species. Appl Environ Microbiol 1984; 47: 1146-1149.

16. Dallas WS, Gill MD, Falkow S. Cistrons encoding Escherichia coli heat-labile toxin. $J$ Bacteriol $1979 ; 139$ : 850-858. 